University of Rhode Island

DigitalCommons@URI

Open Access Master's Theses

1981

\title{
The Effect of Forced Warm Swim on Escape Learning in Rats
}

Katherine A. O'Neill

University of Rhode Island

Follow this and additional works at: https://digitalcommons.uri.edu/theses

\section{Recommended Citation}

O'Neill, Katherine A., "The Effect of Forced Warm Swim on Escape Learning in Rats" (1981). Open Access Master's Theses. Paper 1655.

https://digitalcommons.uri.edu/theses/1655

This Thesis is brought to you for free and open access by DigitalCommons@URI. It has been accepted for inclusion in Open Access Master's Theses by an authorized administrator of DigitalCommons@URI. For more information, please contact digitalcommons-group@uri.edu. 
THE. EFFECT OF FORCED WARM SWIM ON ESCAPE LEARNING IN RATS

BY

RATHERINE A. O'NEILL

A THESIS SUBMITTED IN PARTIAI FULFILIMENT OF THE REQUIREMENTS FOR THE DEGREE OF MASTER OF ARTS

IN

PSYCHOLOGY

UNIVERSITY OF RHODE ISLAND

1981 


\section{Abstract}

Recently, an animal model of depression, which appeared to be sensitive to clinically effective antidepressant treatments, was described by Porsolt et al (1978b). The model was derived from the observation that rats forced to swim in inescapable warm $\left(25^{\circ} \mathrm{C}\right)$ water for fifteen minutes become immobile after some time. Immobility was characterized by animals floating in an upright position, with only their heads above water. When retested twenty-four hours later, rats showed significantly longer lengths of immobility than naive controls. The investigators labeled this response "behavioral despair". In the present study, two experiments were performed to further investigate "behavioral despair". In experiment one, rats were exposed to escapable or Inescapable wartm swims of equivalent length, or no swim, and tested twenty-four hours later on duration of immobility and latency to become immobile. It was hypothesized that the inescapable group would exhibit "behavforal despair", while the escapable group would not differ from controls. Results showed that both inescapable and escapable groups were immobile significantly longer than controls, and did not differ from one another. No differences were found among groups on latency to become 1mmobile. In a second experiment, rats were pretreated as in experfment one, and twenty-four hours later were tested on an FR 3 bar press escape task. It was hypothesized that the inescapable groups would have significantly longer latencles to escape shock than both controls and the escape group. Results 
showed no significant differences among groups on latency to escape shock. Results of both experiments are discussed in terms of the water escape task used, and fmplications for the behavioral despair model. While no firm conclusions can be drawn regarding the approprtateness of the water escape task used, it was concluded that behavioral despair does not generalize to a shock escape task. Suggestions for future research are made. 


\section{ACRNOWLEDGEMENTS}

I would like to thank the members of my thesis committee, Dom Valentino, Nelson Smith, John Stevenson, Doran French and Dave Morton for their advice in the theoretical development of this study as well as its actual execution. Very special appreciation goes to my major professor, Dom Valentino, for his suggestions, insights, and patience.

I would also like to acknowledge the valuable assistance of my fellow graduate students, Joe Rossi and Pat Seymour. Joe, very generously performed the power analysis, and both Joe and Pat provided me with many interesting, stfmulating encouraging discussions throughout the course of this project. Thanks also goes to Paul Joubert for his help in data collection. 


\section{Table of Contents}

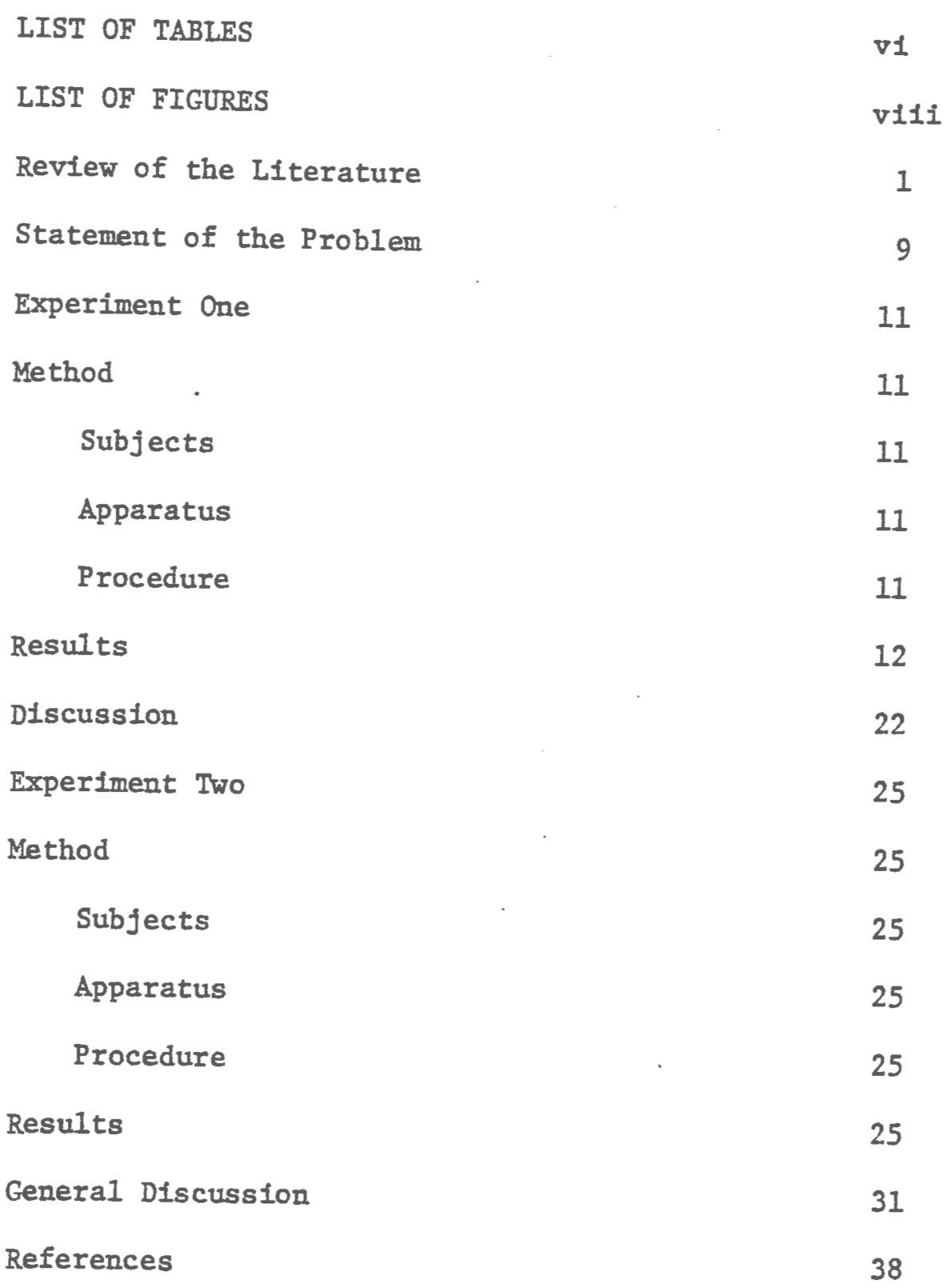




\section{List of Tables}

Table

Page

1. Means and standard devlations of latency to escape from water across trials for escapable group on day one of experiment one.

2. Frledman test on latencles to escape from water across trials for escapable group on day one of experiment one.

3. Means and standard deviations of latency to become Inmobile and duration of immobility for all groups on day two of experiment one.

4. Kruskal-Wallis test on duration of immobility

across groups for day two of experiment two.

5. Mann-Whitney test on duration of immobility for escapable and control groups on day two of experiment one.

6. Mann-Whitney test on duration of fmmobility for inescapable and control groups on day two of experiment one.

7. Mann-Whitney test on duration of 1mmobility for escapable and inescapable groups on day two of experiment one.

8. Summary Table of One-Way ANOVA across groups on latency to become immobile on day two of experiment one. 
9. Means and standard deviations of latency to escape shock for all groups, on day two of experiment two.

10. Summary Table of Two-Way ANOVA (Groups X Trials) on latency to escape shock, on day two of experiment two.

11. Percent of subjects per group meeting specified criterla on day two of experiment two.

12. Power analysis of experiment two. 


\section{List of Figures}

Figure

Page

1. Mean latencies to escape from water across trials, for escapable group on day one of experiment one.

2. Mean duration of imobility for all groups on day two of experiment one.

3. Mean latency to become immobile for all groups on day two of experiment one.

4. Mean latencles to escape shock across trials for all groups on day two of experiment two. 
Review of the Literature

Learned He1plessness

In 1967, Overmeir and Seligman reported that dogs prevlously exposed to Inescapable shock were subsequently unable to learn to escape or avold shock. A second study (Seligman Maier, 1967) was designed to determine whether the deficit in escape/avoidance behavior was the result of the Inescapability and unpredictablifty of the shock, or shock per se. A triadic design was used, in which the control group recieved no pretreatment, a second group was given escape training, and a third group was yoked to the second. The yoked animals received shock of identical duration, intensity and number as their partners in group two. Only the yoked group falled to learn to escape shock, ind1cating that performance deficits were due to the Inescapability and unpredictablifty of the shock, and were not related to the shock 1tself.

Early attempts to reproduce this phenomenon in rats met with limited success. Rats that were exposed to inescapable shock were slow to learn to escape shock, but the deficits were minimal when compared with those observed in dogs (Weiss, Kreickhaus \& Conte, 1968). When rats were treated with varlous amounts of inescapable shock, and later tested on a jump-up escape task, faflure to escape occurred as an Increasing function of the pretreatment shock frequency (Looney \& Cohen, 1972). Others reported that exposure to inescapable shock did not result in failure to learn the escape contingency in a shuttle box, regardless of the number, intensity, or temporal duration between shocks (Maier, Albin \& Testa, 1973). However, these same investigators found that if escape learning was tested using an FR 2 shuttle or wheel turning tasks, rats did show escape faflures. Later studies confirmed 
that in rats, the complexity and/or difficulty of the escape or avoidance task is a critical factor (Seligman \& Beagley, 1975; Glazer \& Welss, 1976). It appears that inescapably shocked rats fail to learn only those responses that are gradually learned and voluntary, rather than easily learned and reflextve.

Seligman (1975) called this phenomenon "learned helplessness", hypothesizing that during exposure to inescapable aversive stimulation, the organism learns that responses and reinforcements (outcomes) are independent. This learning quickly and easily generalizes, resulting in serfous motivational, cognitive and emotional disturbances. Given some similarities between learned helplessness and depression in terms of: 1) behavioral symptoms, 2) etlology or cause, 3) effective treatments, and 4) prevention, Seligman (1975) has suggested that learned helplessness may provide a useful animal model of depression. Simflartites Between Learned Helplessness and Human Depression Behavioral Symptoms

In order for a behavior to be considered pathological, it must be shown to be inapproprlate or maladaptive. It has been suggested that in depression, the response to some stressful experience (usually uncontrollable 10ss) generalizes inapproprlately. A number of studies demonstrate that learned helplessness induced in the lab in nondepressed human subjects produces defictts very similar to those shown by mildly depressed subjects. Difflculty is solving anagrams (Klein \& Seligman, 1976; Miller \& Seligman, 1975) and distorted perception of responsereinforcement independence (Miller, Seligman \& Kurlander, 1975; Gatchel Paulus \& Maples, 1975) are found in both groups. 
Beck (1967) reported that as a symptom, negative expectations showed the highest correlation with clinical ratings of depression. He suggests that this negative cogitive set is central to the development of other depressive symptoms. That is, the bellef that one's actions have negligible effects on the environment results in the symptoms of hopelessness and loss of motivation. Other examples of this view are provided by Bibring (1953), who observes, "The depressed person ... has lost his incentives and gives up, not the goals, but pursuing them since this proves to be useless". Similarly, Melges and Bowlby (1969) state, "Our thesis is that while a depressed patient's goals remain relatively unchanged, his estimate of the liklihood of achieving them and his confidence in the efficacy of his own skilled actions are both diminished." Thus, depression in some cases, may begin as a response to a situation in which the individual has lost control over sources of reinforcement as well as the ability to avoid or escape aversive events. The response to such an occurrence may be passivity, having learned that responses are ineffectual. Pathological depression may then develop as the Individual begins to generalize this response, and percelves bfm- or her-self to be generally powerless, hopeless, helpless and ineffective. An analogous course of events has been observed in varfous laboratory studies of helplessness in animals. It has been demonstrated that "h elpless" behavior generalizes outside of the situation in which animals were exposed to inescapable aversive stimulation. A number of investigators have reported that rats exposed to inescapable shock in one apparatus will exhibit helplessness when tested on a shock escape task In another apparatus (Seligman \& Beagley, 1975; Seligman, RoselIIn1 \& Kozak, 1975; Glazer \& We1ss, 1976). Thus, the phenomenon does 
appear to generalize across situations.

Other studies indicate that helplessness also generalizes across aversive stimuli. Braud, Wepman \& Russo (1969) pretreated animals with either inescapable shock, or allowed them to escape shock by climbing a pole. Twenty-four hours later, subjects were tested on a warm water escape task. The antmals that received inescapable shock showed an increase in swimming time when compared to animals in the escapable group and nonshocked controls. In another study, rats were pretreated with either escapable or inescapable shock or cool water swin (Altenor, Ray \& Richter, 1977). As expected, animals pretreated with inescapable shock or swim were subsequently unable to learn to escape from shock or water, respectively. In addition, rats pretreated with inescapable shock showed slower and fewer escapes from the water maze, and rats pretreated with inescapable swim showed slower and fewer escapes from shock.

Thus, learned helplessness appears to generallze, resulting in maladaptive behavior, similar to that seen in depression.

\section{Reversal of Learned Helplessness and Depression}

One technique that has consistently reversed the defictts in escape learning that characterize learned helplessness in dogs, was 1iterally dragging the animals by thelr leashes across the shuttle box to show them that thls behavior would terminate shock (Sel1gman et al, 1968). Simflarly, pulling rats across an operant chamber, and leaning them on the lever resulted in all previously "helpless" subjects acquiring the appropriate escape task (Seligman, Rosellinl \& Kozak, 1975).

Thus, learned helplessness can be reversed in dogs and rats by teaching the animal that its responses can affect outcomes. Many 
therapies for depression induce the patient to regatn operant control (Seligman, Klein, \& Miller, 1976). By definition, all Instrumental behavior theraples arrange contingencles such that the patients responses control the presentation of refnforcement (Herson et al, 1973; Reisinger, 1973). It is postulated that as the patient recognizes the relationship between his/her responses and environmental events, depression will be allevlated. Lewinsohn et al (1969) control the amount of therapy time by the patient's participation in activities and other nondepressed behavior.

More recently, it has been reported that learned helplessness can be reversed by the clinically effective tricyclic antidepressant drugs. In one study (Leshner et al, 1979), rats were treated for seven days after inescapable shock with elther one or two dally injections of desmethylimipramine. A dose-dependent effect was observed in which increasing doses of the drug significantly decreased latencles to escape shock, as compared to saline treated controls. Sherman et al (1979) treated rats efther acutely or chronically with imipramine, lorzepam or chlorpromazine and tested them in a learned helplessness paradigm. Chronic, but not acute administration of imipramine specifically prevented helplessness. In addition, brain levels of drug were highly correlated with reduction of escape fallures. The authors concluded that the learned helplessness model appears to be a neuropharmacologically relevant animal model of depression. Other Animal Models of Depression Separation - Induced Depression in Monkeys

A number of independent investigators have demonstrated that 
separation of infant macaque monkeys from their mothers results in a behavioral syndrome very similar to that observed in human anaciftic depression (Hinde, Spencer-Booth, \& Bruce, 1966;Raufman \& Rosenblum, 1967; Schlottman \& Seay, 1972; Seay, Hansen \& Harlow, 1962). Initlally after separation, infants exhlbited screaming, crying and random, disoriented movements. This pattern of behavior is characteristic of what has been called the "protest" phase. The second phase, or "despair" phase becomes evident as the length of separation from mother is increased. Infants' vocalizations decrease, and significant decreases in preseparation behaviors are observed. Little contact is seen between the Infants, and play behavior is significantly decreased.

Suoml \& Harlow (1977) have proposed that this phenomenon may provide an animal model of depression, given the parallels between the infant monkeys behaviors and the behaviors observed in anaclitic depression by Bowlby and Spitz.

In addition, Suomi (1976) reported that the length of separation is a critical variable in the determination of the course of the infants reaction and the extent of the long-term consequences on the Infant's behavior. This parallels the findings of Spitz (1946), who noted that prognosis for recovery was poorer, the longer anaclitically depressed human Infants remained separated from their mothers.

Another parallel between infant monkeys separation response and human anaclitic. depression is seen in the effect of the post-separation environment. Harlow \& Suom1 (1974) observed that infant monkeys separated from their mothers, but in the company of other adult females showed less severe reactions. The same effect appears to occur in 
human infants, also (Robertson \& Robertson, 1972).

Further evidence in support of this animal model is found in a number of pharmacological investigations. Trifluroperazine, dextroamphetamine and oxazepam all failed to modify behavioral deficits seen in soclally 1solated chimps (Menzel et al, 1963; Turner et al, 1969). chlorpromazine also failed to increase the frequency of social behavior In soclally isolated infant monkeys (Mckinney et al, 1973).

However, imipramine treatment has been reported to produce some behavioral improvement in young rhesus monkeys that were repeatedly subjected to peer separation (Suomi et al, 1978). In another study, administration of desmethylimipramine for a week prior to and during two weeks of infant monkeys' separation from mother, significantly reduced behaviors typlcal of the "despalr" phase (Brinda et al, 1979). Soclal behaviors were particularly affected.

The specific action of antidepressants (as opposed to other psychoactive agents) on the separation reaction in monkeys suggest that this may be a valuable model of depression, albeit a costly one. Behavioral Despair Model

Most recently, a very simple animal model of depression was proposed by Porsolt et al (1977). These investigators descrfbed an easy and practical screening test, which they belfeved to bear some resemblance to clinical depression. The model was based on the observation that when rats were forced to swim in an Inescapable tank, after some time, they became immobile. Animals did not make any further attempts to escape and simply. floated in an upright position, keeping only their heads above water. Rats exposed to this forced swim showed significant1y longer lengths of immobility when retested twenty-four hours later, 
as compared to naive controls. It was suggested that this easily identiflable behavior reflected a state of "despair" in the rat, not unlike learned helplessness.

A number of clinically effective antidepressant treatments have been shown to significantly decrease the length of Immobility in rats exposed to the forced warm swim. These treatments Include electroconvulsive shock, REM deprivation, exposure to an "enriched" environment, and various antidepressant drugs. In addition, all clinlcally effective "atypical" antidepressant drugs produced a significant reduction in immobility. The antidepressant actions of these compounds has been heretofore difficult to predict on the basis of pharmacological profiles, since these agents differ from the classic antidepressants (tricyclics and MAO-I's) on the basis of both chemical structure and pharmacological activity.

The simplicity, practicality and low cost of the behavioral despair model make it an excellent candidate for use as a screening procedure to detect the efficacy of antidepressant drugs. In addition, the finding that atypical antidepressants are effective in reversing "behavioral despair" suggests that this procedure may be capable of detecting antidepressant agents that were prevlously undetected by classical screening techniques. For these reasons, the behavioral despair model 1s widely used in industrfal neuropsychopharmacology laboratories. In one report from the industry, the behavioral despalr model did detect antidepressant activity (Browne, 1979). Other investigators have simplified the technique even further for use with mice (Wallach \& Hedley, 1979). 
Statement of the Problem

The behavioral model offered by Porsolt and his coworkers is an appealing one. It's simplicity and practicality would seem to make it espectally useful as a technique for screening possible antidepressant treatments. However, this model has some serious flaws. Porsolt's arguments in support of behavioral despair as an animal model of depression are based on the findings that imobility is reversed by clinically effective antidepressant treatments. No theoretical explanation is offered for any similaritles between the etiology of depression and the causative factors in behavioral despair. In addition, the behavior exhibited by rats in the behavioral despair paradigm seems to be adaptive. The animals appear to "give up" and become Immobile, thus conserving energy where 1ts expenditure would be ineffectual. It is clear that an adaptive response cannot serve as an analog of a maladaptive behavior.

In contrast, the learned helplessness model appears to provide an analog of some types of clinical depression (Seligman, 1975). It has been shown that helplessness produced in the laboratory bears simflar1ty to depression in terms of symptoms, etiology and effective treatments. Perhaps the most sallent behavioral feature of learned helplessness is that it generalizes. The generalization of helplessness is crucial to the argument that it represents an analog of depression. Anfmals that cannot leam to escape from an aversfve stimulus seem to be exhtbiting maladaptive generalization. While Porsolt et al (1978b) note that there are some parallels between behavforal despafr and learned helplessness, their investigations did not test whether rats exposed to an inescapable swim will subsequently have difficulty 
learning an escape task.

Therefore, the purpose of the present experiments was twofold. Experiment one was conducted in order to replicate the results of Porsolt et al $(1978 \mathrm{a}, \mathrm{b})$, and secondly, to investigate the effect of an escapable swim on "behavioral despair". It was hypothesized that:

1) as reported by Porsolt, anfmals in the inescapable condition would be immobile significantly longer than controls during the day two test; and 2) animals in the escape condition would be immobile for significant1y shorter periods of time than animals in the inescapable condition during the day two test. The purpose of the second experiment was to determine whether exposure to an escapable or inescapable swim had any effect on the animals subsequent performance on an escape task. It was hypothesized that rats exposed to an inescapable swim would show significantly longer latencies to escape shock than both controls and animals in the escape condition. 
Experiment One: The effect of escapable and Inescapable warm swim on "behavioral despair".

Method

Subjects. Thirty-six male Sprague-Dawley albino rats, obtained from Charles River Laboratorles served as subjects. Animals weighed approximately 200-250 grams and were individually housed on a $12 \mathrm{hr}$. light - $12 \mathrm{hr}$. dark cycle in a temperature and humidity controlled room. All rats were handled every day from arrival in the colony until the start of the experiment. Food and water were available ad libitum.

Apparatus. The apparatus consisted of a $96 \mathrm{~cm}$. high cylindrical plastic pail, with a diameter of $31 \mathrm{~cm}$. The pail was filled to a helght of $18 \mathrm{~cm}$. with $25^{\circ} \mathrm{C}$ tap water. An $8 \mathrm{~cm}$. wide wire mesh ladder, $75 \mathrm{~cm}$. In length was used on escape trials.

Procedure. Animals were randomly assigned to one of three groups: escapable, Inescapable, and control. On day one, animals in the escapable group were placed in the warm water, and after three minutes, the wire mesh ladder was lowered into the water. Latency to escape via the ladder was measured. Anfmals in this group recelved five three minute trials, with a one minute intertrial interval. When escape latencles were taken into account, actual trlal lengths ranged from 3.03 to 3.57 minutes. Animals in the inescapable group were placed in the warm water for fifteen minutes. Animals in the control group received no treatment.

Twenty-four hours later, all animals were placed in the warm swim for five minutes. Latency to become immobile and duration of immobility were recorded. The animal was considered to be immobile whenever it remained floating passively in the water in an upright position, with its 
head just above the surface of the water. Results of Experiment One

Means and standard deviations of latency to escape from water for the escapable group on day one are presented in Table 1. Results of an F-max test indicated that the varlance was heterogeneous (F-max (5, 5) $=43.24 ; \mathrm{e}^{<.01)}$. Therefore, a Friedman test was performed, as shown In Table 2. Results of the Friedman test demonstrated no significant decreases in latencies to escape across trials $\left(\chi^{2}(4)=3.59\right.$; p $\mathbf{0 5}$ ). Meen latencles to escape across trials are illustrated in Figure I.

Means and standard deviations of latency to become inmobile, and duration of immobility on day two for all groups are shown in Table 3. Results of an Pmax test on duration of immobility indicated that the verlance was heterogeneous $(\underline{F}-\max (10,3)=7.65 ; \mathrm{R}<.01)$. Therefore, a Rruska1-Wallis test was performed, as presented in Table 4. Results of the Kruskal-Wallis test indicated that there was a significant difference among groups on duration of imobility $($ E $(2)=9.4 ; p<.01)$. Mean durations of immobility for all groups are illustrated in Figure 2. Further analyses with Mann-Whitney tests showed that rats in the escapable condition were immobile significantly longer than controls $(\mathrm{U}(12)=29 ; \mathrm{P}<.01)$, as shown in Table 5. In eddition, animals in the inescapable group also showed significantly longer durations of imobility than controls (U $(12)=24 ; \mathrm{R}<.01$ ), as shown in Table 6 . As shown in Table 7, there were no significant differences between the escapable and inescapable groups on duration of immobility (U (12) $=63 ; \mathrm{p}>.05)$ 
Table 1

Latency $^{a}$ to Escape from Water,

Day One of Experiment One.

\begin{tabular}{|c|c|c|}
\hline Trlal & $\bar{X}$ & SD \\
\hline 1 & 13.06 & 13.78 \\
\hline 2 & 7.62 & 6.46 \\
\hline 3. & 5.60 & 2.73 \\
\hline 4 & 3.80 & 1.31 \\
\hline 5 & 6.78 & 8.82 \\
\hline
\end{tabular}

atencles measured in seconds 
Table 2

Latency to Escape Across Trials, Friedman Test

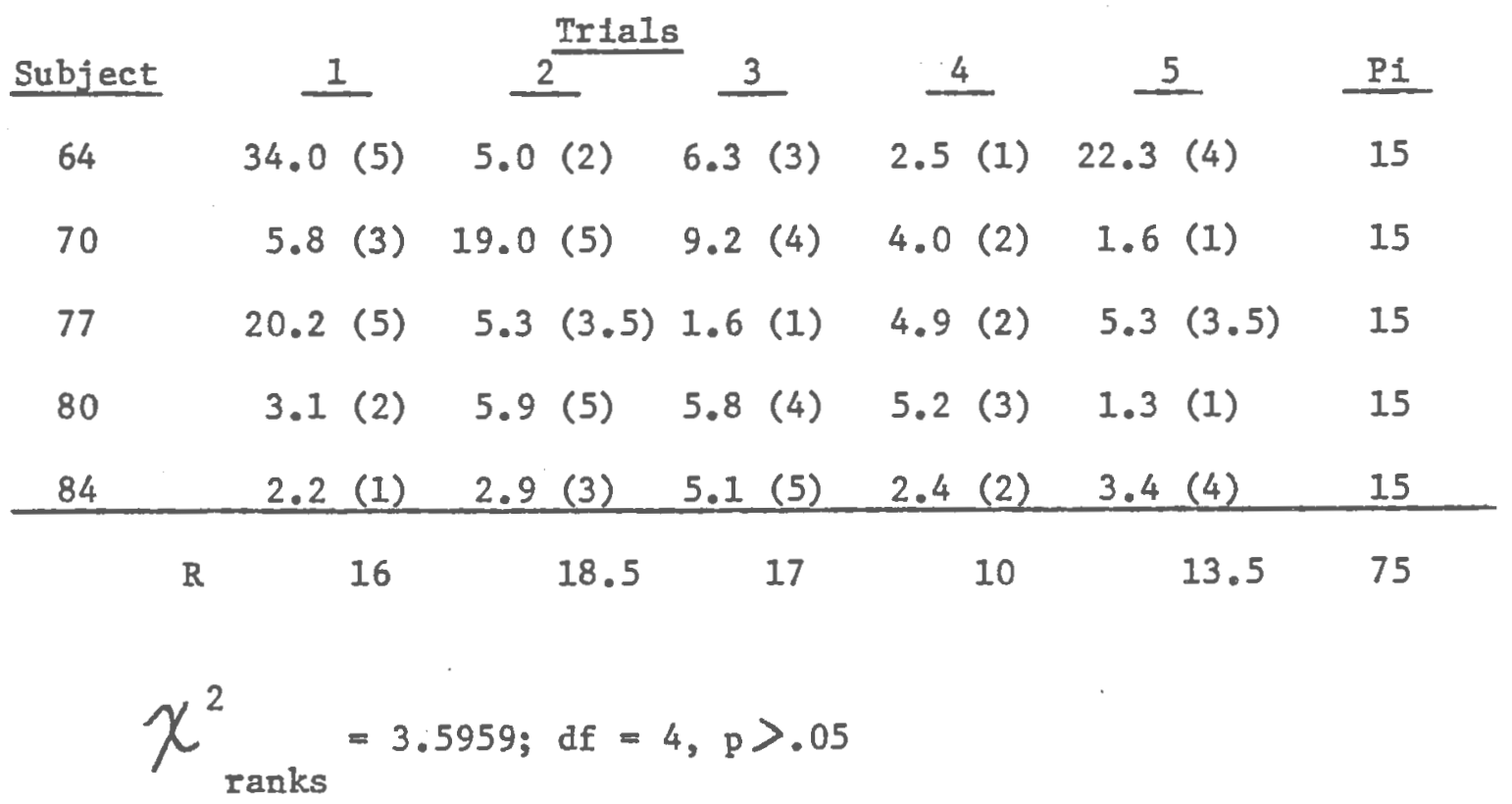



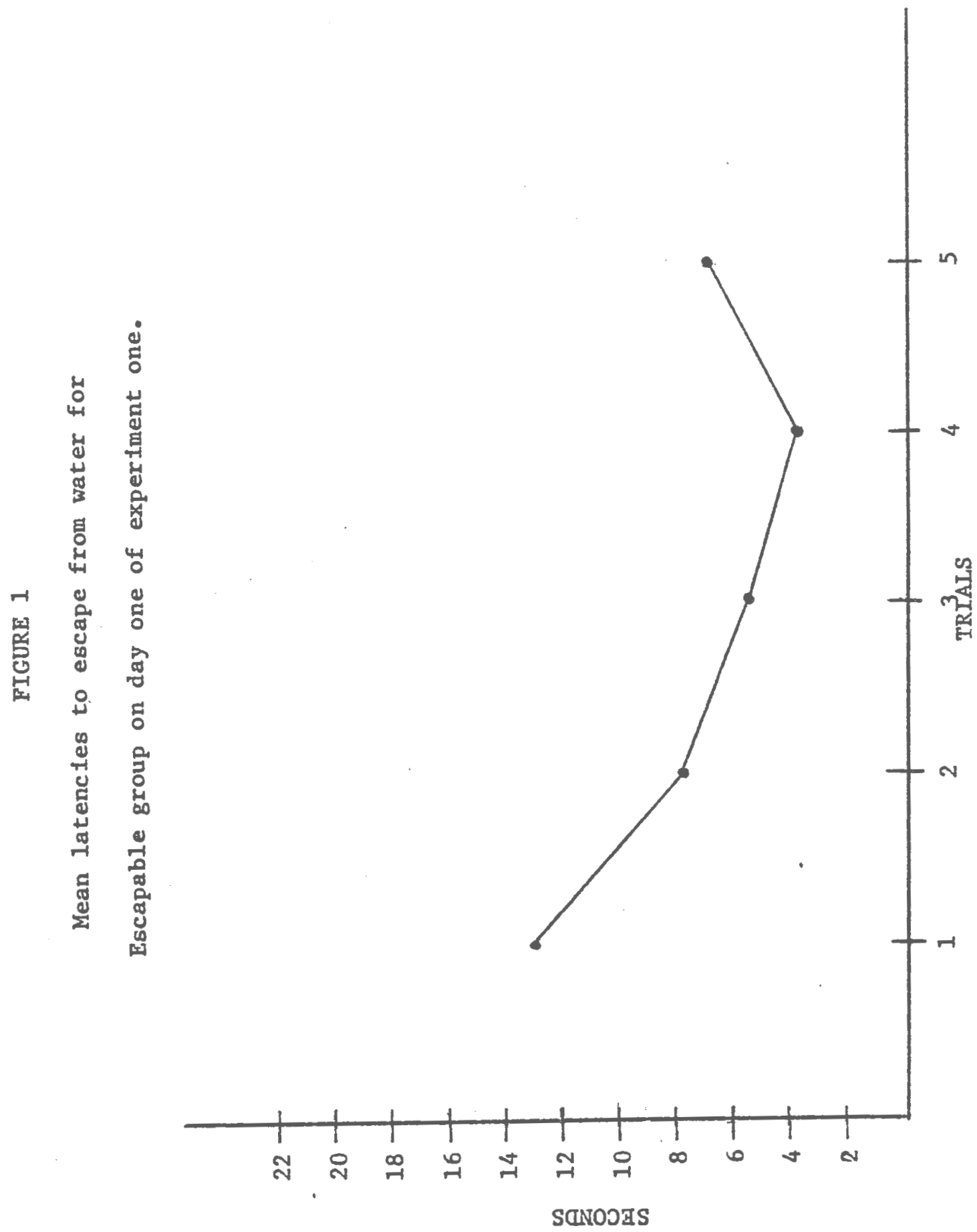
Table 3

Latency to Become Immobile and

Duration of Immobllity,

Day Two of Experiment One.

Groupa

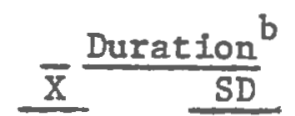

$72.21 \quad 28.73$

120.12 * 48.35

$139.16^{*}$

67.19

Inescape

Control

Escape

$139.16 *-67.19$

$a_{N}=12$

${ }^{b}$ reported in seconds

* $<.01$ 
Table 4

\author{
Duration of Immobility \\ Kruskal - Wallis
}

Test

Controls

Escape

Inescape

Scores Ranks

Scores Ranks

Scores Ranks

\begin{tabular}{|c|c|c|c|c|c|}
\hline 72.4 & 11 & 52.9 & 5 & 63.37 & 7 \\
\hline 77.2 & 13 & 125.5 & 25 & 105.2 & 18 \\
\hline 101.8 & 17 & 167.3 & 32 & 124.5 & 23 \\
\hline 17.4 & 1 & 33.6 & 3 & 131.7 & 26 \\
\hline 116.8 & 20 & 162.2 & 31 & 81.1 & 15 \\
\hline 63.5 & 8 & 154.2 & 29 & 254.3 & 36 \\
\hline 32.0 & 2 & 90.8 & 16 & 39.1 & 4 \\
\hline 53.8 & 6 & 150.6 & 28 & 142.6 & 27 \\
\hline 76.0 & 12 & 187.0 & 33 & 192.1 & 34 \\
\hline 79.0 & 14 & 121.4 & 21 & 160.9 & 30 \\
\hline 105.3 & 18 & 72.6 & 11 & 250.3 & 35 \\
\hline 71.3 & 9 & 122.1 & 22 & 124.8 & 24 \\
\hline $\mathbf{R}$ & 131 & & 256 & & 279 \\
\hline
\end{tabular}



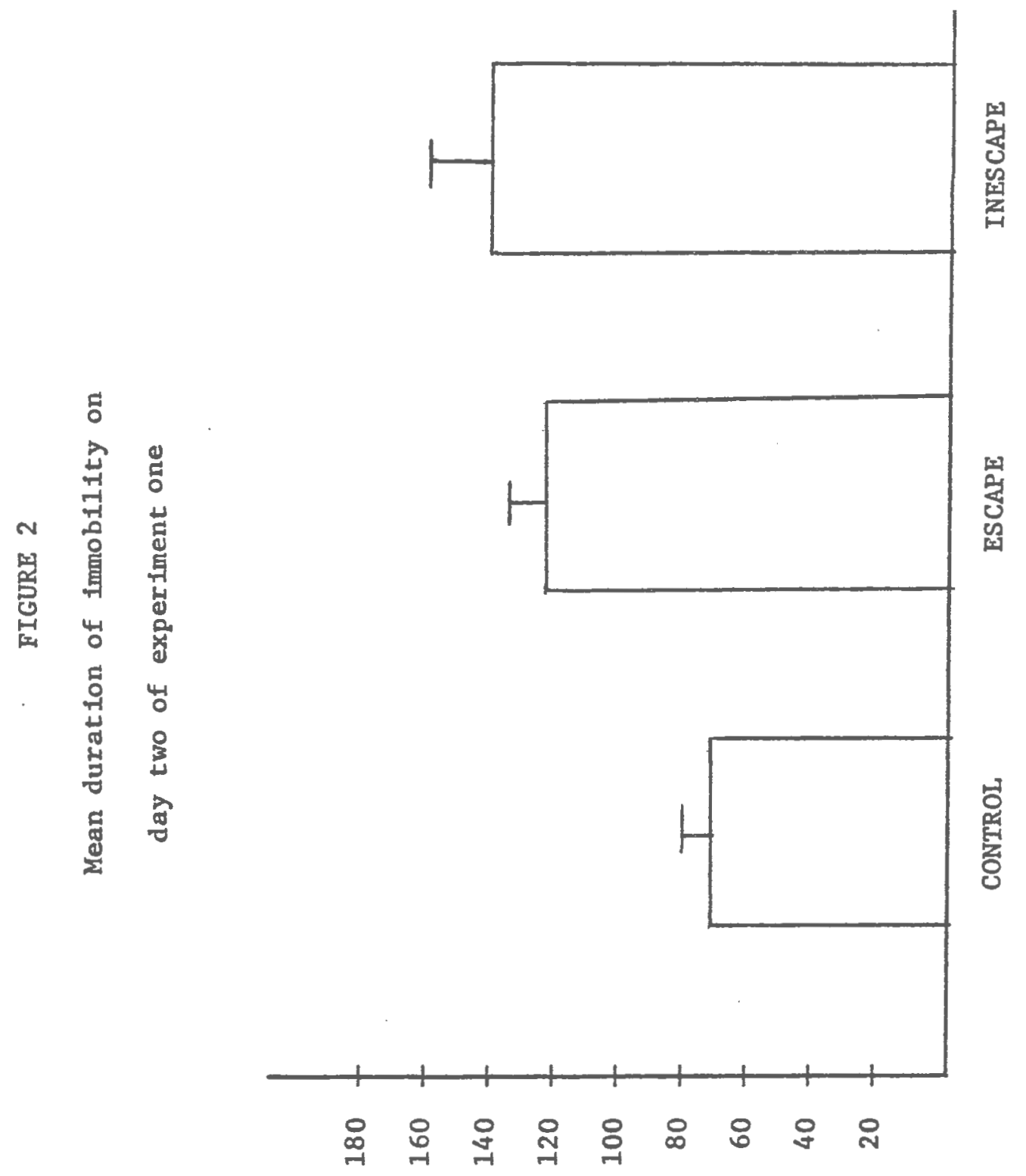

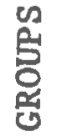
SaNOOHS 
Table 5

$$
\begin{aligned}
& \text { Duration of Immobility } \\
& \text { Mann - Whitney Test }
\end{aligned}
$$

\begin{tabular}{|c|c|c|c|}
\hline \multicolumn{2}{|c|}{ Control } & \multicolumn{2}{|c|}{ Escape } \\
\hline Scores & Ranks & Scores & Ranks \\
\hline 72.4 & 8 & 52.9 & 4 \\
\hline 77.2 & 11 & 125.5 & 19 \\
\hline 101.8 & 14 & 167.3 & 23 \\
\hline 17.4 & 1 & 33.6 & 3 \\
\hline 116.8 & 16 & 162.2 & 22 \\
\hline 63.5 & 6 & 154.2 & 21 \\
\hline 32.0 & 2 & 90.8 & 13 \\
\hline 53.8 & 5 & 150.6 & 20 \\
\hline 76.0 & 10 & 187.0 & 24 \\
\hline 79.0 & 12 & 121.4 & 17 \\
\hline 71.3 & 7 & 122.1 & 18 \\
\hline 2.48 & & & \\
\hline .0 & & & \\
\hline
\end{tabular}


Table 6

Duration of Immobility

Mann - Wh1tney Test

Contro1

Scores Ranks

72.48

77.210

$101.8 \quad 13$

17.41

$116.8 \quad 16$

63.56

32.0

76.0

79.0

105.3

71.3

$$
\begin{aligned}
& z=2.77 \\
& p<.01
\end{aligned}
$$

Inescape

Scores Ranks

63.45

$105.2 \quad 14$

$124.5 \quad 17$

$131.7 \quad 19$

$81.1 \quad 12$

$254.3 \quad 24$

$142.6 \quad 20$

$192.1 \quad 22$

$160.9 \quad 21$

$250.3 \quad 23$

$124.8 \quad 18$ 


\section{Table 7}

Duration of Immobility

Mann - Whitney Test

Escape

Scores Ranks

$52,9 \quad 3$

$125.5 \quad 13$

$167.3 \quad 20$

$33.6 \quad 1$

$162.2 \quad 19$

$154.2 \quad 17$

$90.8 \quad 7$

$150.6 \quad 16$

$187.0 \quad 21$

121.4

72.6

122.1

3

core

63.4

105.2

124.5

131.7

81.1

254.3

24

39.1. 2

$142.6 \quad 15$

192.1

22

$160.9 \quad 18$

250.3

23

124.8

12

$$
\begin{aligned}
& z=0.51 \\
& p>.05
\end{aligned}
$$


Results of an F-max test on latency to become Immoblle indicated that the varlance was homogeneous $(F-\max (10,3)=2.12 ; \mathrm{p}>.05)$. Therefore, a one way ANOVA was performed, and the summary table is presented In Table 8. Results of the ANOVA demonstrated no significant differences among groups in terms of latency to become immobile $(\underline{F}(2,33)=$ 2.32; $\mathrm{P}$ >.05). Mean latencles to become Immobile for all groups are illustrated in Figure 3.

Discussion of Experiment One Results

The results of experiment one replicate the findings reported by Porsolt et al (1978b). Animals in the inescapable group were immobile significantly longer than controls. Animals in the escapable group were also immobile significantly longer than controls, but did not differ from the inescapable group. This may have been related to the "escapability" of the escape task. Rats in this group did not display a significant decrease in latency to escape from water during the day one treatment, suggesting that they did not learn to escape.

In contrast, no significant differences in latencles to become Immoblle were found among groups. Porsolt et al (1978a,b) did not use latency as a dependent measure, and it appears that latency to become immobile is not a salient measure of "behavioral despair".

However, since the findings originally reported by Porsolt et al (1978b) were confirmed, experiment two was conducted in order to test the generalizability of "behavioral despalr". 
Table 8

Summary of Analysis of Varlance On

Latency to Become Immobile

\begin{tabular}{lcccc} 
Source of Varlance & SS & df & MS & F \\
\hline Group & 8215.995 & 2 & 4107.997 & 2.32 \\
Error & 58499.485 & 33 & 1772.712 &
\end{tabular}



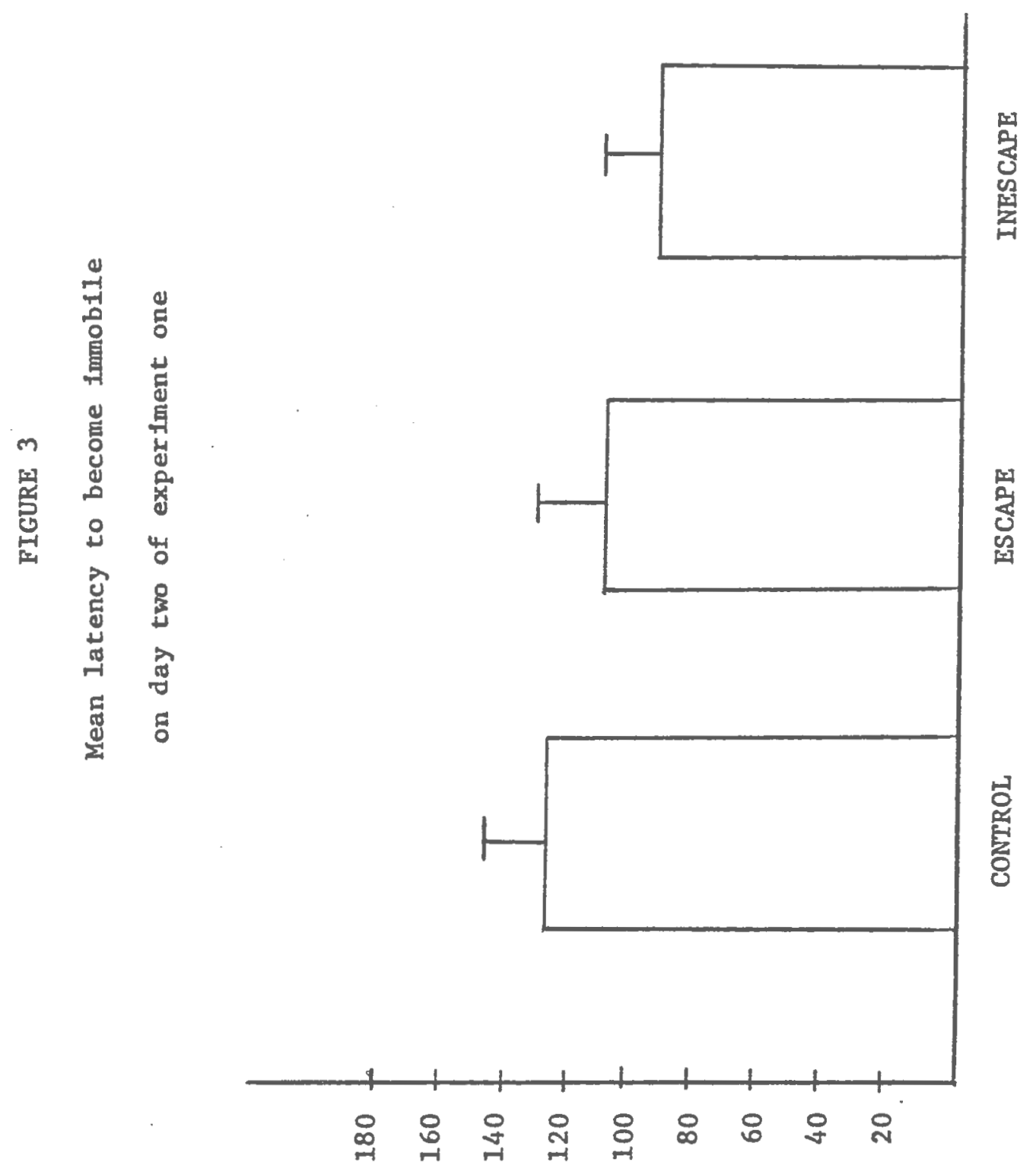

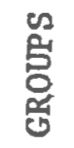
sanoวas 
Experiment Two: The effect of escapable and inescapable warm swim on escape from shock.

Method

Subjects. Thirty-one male Sprague-Dawley albino rats served as subjects, as described above.

Apparatus. Apparatus for swim procedures was as described above. Shock escape testing took place in a standard operant chamber, with electrifled grid floor and wall lever. Scrambled shock of $2.0 \mathrm{~mA}$ was generated by a shock generator and scrambler. Latencies to escape shock by lever press were recorded electromechanically.

Procedure. Animals were randomly assigned to one of three groups: escapable, Inescapable, and control. Day one treatments were Identical to those described for comparable groups in experiment one. On day two, animals in all groups were tested on the escape task. Rast were placed In the operant chamber, and 40 trials of 2.0 ms shock were presented through the grid floor on a VI $60 \mathrm{sec}$. schedule. Trials 1 through 5 required one bar press to escape shock (for the purpose of shaping), and trials 6 through 40 were on an FR 3 schedule. If the escape response was not made w1thin 60 seconds after presentation of shock, the shock automatically terminated. These parameters were chosen on the basis of results from p1lot studles and the results reported by Maler, Albin \& Testa (1973).

Results of Experiment Two

Table 9 shows the means and standard deviations of latencles to escape shock. Results of an F-max test indicated that the varlance was homogeneous $(\underline{F-\max }(7,9)=2.51 ; \mathrm{p}>.05)$. Latencles were analyzed in blocks of five consecutive trials. Mean latencles on trials one 
Table 9

Latencies to Escape Shock

Across Blocks of Five Trials,

Day Two of Experiment Two

Groups $^{a}$

Blocks

1

2

3

4

5

6

7

8
Control

$\underline{\bar{X}} \quad \underline{S D}$

$10.20 \quad 5.65$

$26.11 \quad 19.56$

$26.41 \quad 22.98$

$32.47 \quad 25.34$

$30.79 \quad 24.48$

$27.19 \quad 25.88$

$25.51 \quad 27.36$

$27.53 \quad 27.02$
Inescape

$\underline{\bar{X}} \quad \underline{S D}$

15.0912 .46

35.8019 .04

$34.77 \quad 23.19$

28.7923 .79

$25.56 \quad 22.03$

$37.14 \quad 25.51$

34.4725 .79

$30.48 \quad 26.44$
Escape

$\overline{\mathrm{X}} \quad \mathrm{SD}$

$9.39 \quad 7.83$

$29.28 \quad 17.32$

28.3918 .90

32.6718 .92

28.4922 .71

$27.66 \quad 22.68$

25.2024 .43

26.1924 .14

a

$\mathrm{N}=11$ for control, 10 for other groups.

Note: latencies expressed in seconds. 
through five were excluded from analysis, since the purpose of these trlals was to provide an opportunity for response shaping, rather than serving as a dependent measure of a treatment effect. A two way analysis of varlance was performed, as summarized in Table 10. Results of the analysis showed no significant differences among groups on the treatment $(\underline{F}(2,26)=0.50 ; \underline{P}>.05)$ or trial $(\underline{F}(6,156)=0.59 ; \underline{P}>.05)$ factors. There was also no significant interaction $(\underline{F}(12,156)=0.61$; P $>05)$. Mean latencles to escape shock across trials for all groups are illustrated in Figure 4.

Further examination of the data using a number of different criteria revealed no rellable differences among the groups, as shown in Table 11 . 
Table 10

Summary of Analysis of Variance On

Latencies to Escape Shock

\begin{tabular}{lrrrr} 
Source of Variance & SS & df & MS & F \\
\hline Group & 344.608 & 2 & 172.304 & 0.05 \\
Error & 90420.801 & 28 & 3229.314 & \\
Trials & 1158.053 & 6 & 193.008 & 1.69 \\
Trials X Group & 1856.302 & 12 & 154.691 & 1.36 \\
Error & 19166.967 & 168 & 114.089 & \\
\hline
\end{tabular}


资 嵒

$\begin{cases}1 & 9 \\ 1 & 1 \\ 1 & 1\end{cases}$

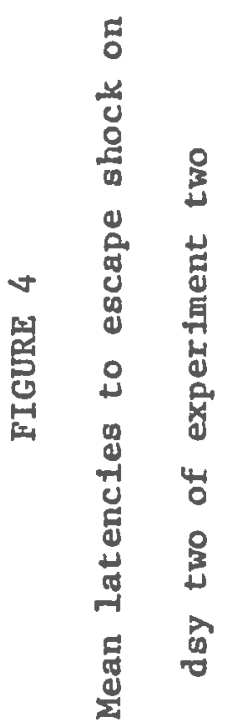

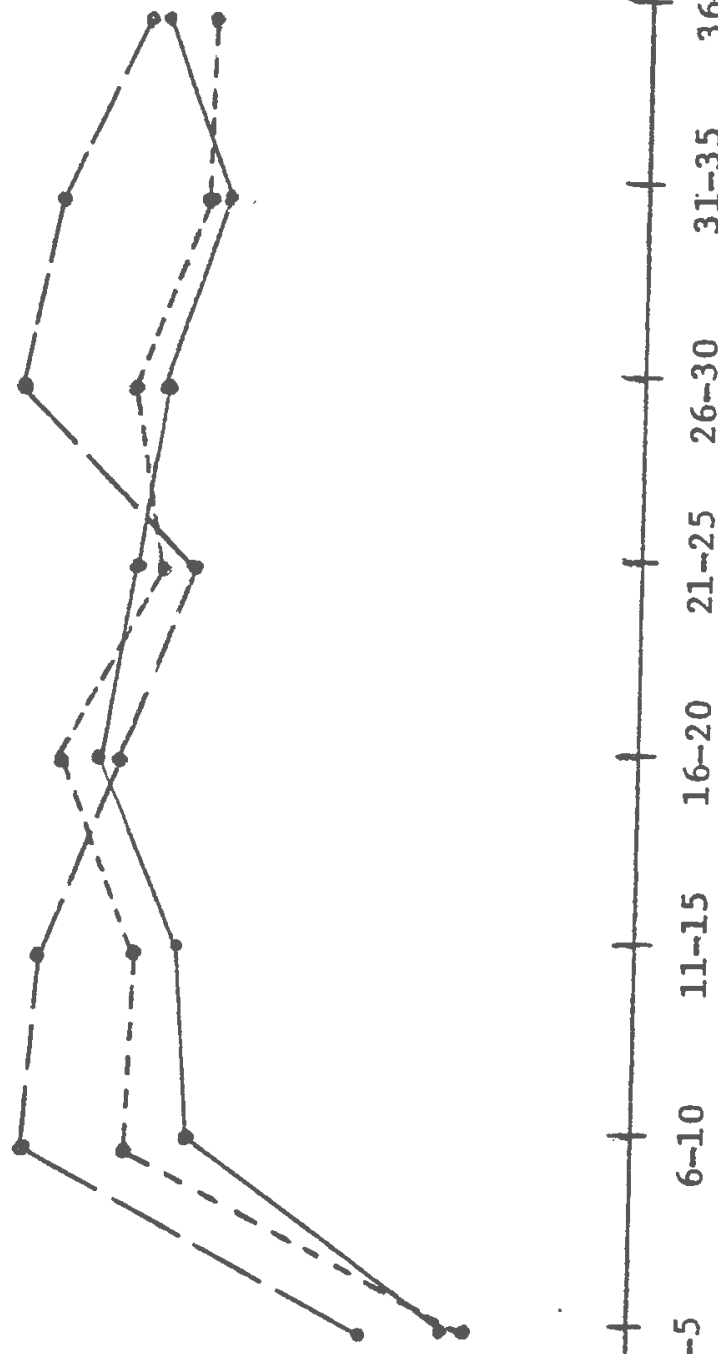

0
$y$
$j$
$m$
$n$
$m$
1
$m$

$+\begin{array}{r}0 \\ -1 \\ \text { v }\end{array}$

N

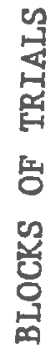

n

S匹NOวHS 
Table 11

Percent of Subjects Meeting Specified Criteria

Group $^{a}$

Criteria

Nonlearners ${ }^{b}$

Learners

Latency ${ }^{c}<10 \mathrm{sec}$.

Latency ${ }^{c}<15 \mathrm{sec}$.
Escape

Inescape

$50 \%$

$36 \%$

$70 \%$

$50 \%$

$64 \%$

$30 \%$

$30 \%$

$64 \%$

$66 \%$

$55 \%$

$55 \%$

${ }^{a} \mathrm{~N}=11$ for control, 10 for other groups.

${ }^{b}$ Nonlearners $=$ animals with latencies $\geqq 55$ seconds across last 20 trials.

$c_{\text {Latency }}=$ mean latency at block 7 . 


\section{Discussion}

The purpose of experfment one was to replicate the findings reported by Porsolt et al (1978b). The Porsolt group demonstrated that rats forced to swim in warm water for fifteen minutes showed signif 1cantly longer durations of immobility than did nalve controls. However, no escapable swim group was tested in the original behavioral despair experiments. If "behavioral despair" is due to inescapable warm swim, then exposure to an equivalent escapable swim should not result in significantly longer durations of imobility than controls.

In the present study, escapability did not prevent behavioral despair, which calls into question the approprlateness of the model. However, it can be argued that there was no true escapable condition. The results of experfment one show that no significant difference in latencles was found across escape trlals for the escapable group on day one. This finding may have been due to the design of the escape condition. Five trials may have been insufficient for escape learning to occur. Also, since $r$ ats were in the water for three minutes before escape was possible, the task may not have been perceived as escapable. Ancther possible confound is that anfmals were in effect punished for escaping, since one minute after crawling up the ladder, they were placed back Into the warm water. Any or all of these factors may bring the escapability of the condition under question. However, there is also some evidence to suggest that animals in the escapable group did learn to escape from the water. Inspection of Figure 2 shows a consistent decrease in escape latencies across trials. The failure of the differences to reach statistical significance may have been related to sever- 
al factors. First, examination of the data Indicates that the mean latency (and standard deviation) for trial five was inflated by the score of one animal. This animal's long escape latency is not representative of the group. Secondly, high varlability among trial one scores would seem to preclude the possibility of obtaining statistical1y significant differences across trials. In addition, there appears to be a "floor" effect - all rats did escape quickly. It is possible that rats do not have to "learn" to climb out of the water - It may be a prepotent response, and the floor effect my be related to this. Thus, it does not seem possible at this time to draw any firm conclusions regarding the escape condition used in this study. The use of a more elaborate escape response might have provided for better clariflcation of this issue. However, the selection of an escape response was IImited, since the escape condition had to be as equivalent to the inescape condition as possible, and the parameters of the inescape condition had to be confined so as to correspond to Porsolt's model.

Results of measurements taken on day two of experiment one show that groups did not significantly differ from one another in terms of latency to become immobile. However, both treatment groups did exhibit significantly longer durations of Immobility than did controls. These results confirm the findings of Porsolt et al (1978b), who reported significant increases in duration of immobility. The Porsolt group did not measure latency to become immobile. Figure 2 shows that while the escapable and inescapable groups did not significantly differ from one another on duration of lmmobility, the escapable group did display shorter durations than the inescapable group. However, animals in the escapable condition did exhibit significantly longer 
durations of Immobility than controls. Taken with the results of the analysis of latencies to escape from water on day one, this finding suggests that either animals in this group did not truly learn to escape, or that prior exposure to warm swin w111 result in longer durations of lmobility during a second exposure, regardless of the escapability of the swim. No conclusions can be drawn on the basis of this data. Further studies are required in order to determine if animals can consistently learn to escape from water, and what effect it would have on "behavioral despair". One possible method for testing animals" ability to escape from warm water might be the use of an underwater maze simflar to one described by Altenor, Kay \& Richter (1977). This could be used in the trladic design described by Seligman (1975), in which rats in the inescapable group are yoked to partners in the escapable group. In this manner, both escapable and Inescapable animals are exposed to the warm swim for equal lengths of time. Such a procedure would require many more than five trials, which would serve two purposes: 1) animals in the escapable group would have a better oportunity to learn to escape, and more data would be avallable on which to assess their performance, and 2) animals in the inescapable group would have sufficlent exposure to the warm swim to produce "behavioral despalr".

It is clear, however, that animals in the inescapable group did show "behavioral despair" as described by Porsolt et al (1978b). If "behavioral despalr" does generalize, as it should to fulf 11 one criterion for an animal model of depression, it would be expected that animals in the inescapable group would show significant defictts 
in learning to escape from shock. Given the results of experiment one, animals in the escapable group might be expected to show similar deficits. Yet animals in both of these groups did not differ from controls on the shock escape task.

Results of experiment two indicated that neither the treatment nor the trial factors had any effect on the latency of rats to escape from shock. Further examination of the data shows that all groups had similar distributions of mean escape latencies across the last thirty-five trials. Inspection of the control group latencies indicates that four out of eleven, or approximately one third of the subjects failed to learn to escape shock. It might be argued that given this rate of failure to learn in controls, it is not surprising that the treatment groups did not show a significantly higher number of escape fallures. It is reasonable, therefore, to question the appropriateness of the escape task. As noted by other Investigators (Seligman \& Beagley, 1975; Maler, Albin \& Testa; 1973), the use of a shock escape task as a measure of learned helplessness in rats can pose varlous problems. The mafor difficulty lies in choosing an escape task that is simple enough for controls to learn, but of sufficient difficulty for "helpless" animals to be unable to learn 1t. An FR3 bar press escape response has been successfully used to discriminate between helpless and nonhelpless rats (Seligman \& Beagley, 1975; Seligman et al, 1975). However, the same investigators also report that consistently, a number of control animals fall to learn the task. Therefore, it is posstble that the escape task used in the present experiment was not sensitive enough to discriminate between helpless and nonhelpless rats. Addi- 
tional Investigations and careful examination of previously reported results may shed some light on this apparently ubiquitous problem.

Power analysis of the experimental design of experiment two ind 1cated that for the design utilized, the probability of detecting any trial or interaction effects that would account for as little as $8 \%$ of the variance was .97 or greater, as shown in Table 12. The design was slightly less powerful for detecting a pretreatment effect, with a probability of .91 for detecting an effect accounting for $33 \%$ of the variance. It should be noted that the manitude of effect as represented by eta squared in Table 12 , is a conservative estimate, such that the power of the design for the respective effect magnitudes is slightly higher. Thus, while the design that was used in experiment two was not of optimal power for detecting a treatment effect, it may be argued that if a treatment effect did occur, it would be expected to account for at least one third of the variance.

Based on the results of the power analysis and the observation that the performance of animals in the Inescapable group did not differ from the two other groups on the shock escape task, it appears unlikely that the inescapable warm swim had any meaningful effect on animals' performance on the shock escape task. Rather, "behavioral despair" may reflect either an adaptive response to a specfic situation, or physical fatigue, or some combination of the two. Neither of these behavioral responses can be considered to be an adequate analog of pathological depression.

Several recent investigations provide further evidence for the nonspecificity of behavioral despair. These reports indicate that a 
Table 12

Power Analysis of Experfment Two

$\begin{array}{lccc}\text { Source of Variance } & \text { df } & \underline{\eta 2} & \frac{1-\beta}{\beta} \\ \text { Groups } & 2,168 & .25 & .78 \\ & & .33 & .91 \\ \text { Trials } & 6,168 & .06 & .95 \\ & & .08 & .995 \\ & & .11 & .995 \\ & & .14 & .995 \\ \text { Groups X Trials } & 12,168 & .06 & .85 \\ & & .08 & .97 \\ & & .11 & .995 \\ & & .14 & .995\end{array}$


number of pharmacological agents other than antidepressants do reverse "behavioral despair" (Schecter \& Chance, 1979; Wallach \& Hedley, 1979). These agents include caffeine, antihistamines and pentobarbital. This lack of specific reversal by antidepressants suggests that the behavioral despair model is an inadequate animal model of depression.

Finally, one caution must be discussed. It is possible that the current designs and methodologies may not lend themselves to the development nor the analysis of an animal model of depression. Just as all humans exposed to aversive stimuli do not subsequently become clinically depressed, all rats exposed to aversive stimulation may not respond homogeneously (Seligman \& Beagley, 1975). Thus, rather than attempting to devise experimental manipulations that produce an effect large enough to reach statistical significance, perhaps the approach should be reversed. That is, a more fruitful strategy might be to carefully examine those subjects within the treatment group that do exhibit a generalization of performance deficits, regardless of whether or not the group significantly differed from others. An analysis of what makes those "helpless" animals different from their group cohorts (other than on the measure of "helplessness") may provide some valuable information for developing animal models of depression, as well as shed light on the etiology of naturally occurring depressions. 


\section{References}

Altenor, A., Kay, E., \& Richter, M. The generality of learned helplessness in the rat. Learning and Motivation, 1977, $\underline{8}, 54-61$. Beck, A.T. Depression: Causes and Treatments. Philadelphia:

University of Pensylvania Press, 1967.

Beck, A.T. Cognitive therapy: Nature and relation to behavior therapy. Behavior Therapy, 1970, 1, 184-200.

Bibring, E. The mechanism of depression. In P. Greenacre (Ed.), Affective Disorders, New York: International Unfversities Press, 1953.

Braud, W. G., Wepmann, B., \& Russo, D. Task and species generality of the "helplessness" phenomenon. Psychonomic Sclence, 1969, 16, 164-165.

Browne, R. G. Behavioral despair in mice detects antidepressant and anticholinergic activity. Federation Proceedings, 1979, 38, 861. Burgess, E. The modification of depressive behavior. In R. Rubin \& C. Franks (Eds.), Advances in behavior therapy. New York: Academic Press, 1968.

Frledman, A.S. Minimal effects of severe depression on cognitive functioning. Journal of Abnormal Psychology, 1964, 69, 237-243. Gatchel, R.J., Paulus, P.B., \& Maples, C.W. Learned helplessness and self-reported affect. Journal of Abnormal Psychology, 1975, 84, 732-734.

Glazer, H.I. \& Weiss, J.M. Long-term and transitory Interference ef-. fects. Journal of Experimental Psychology: Anfmal Behavior Processes, 1976, 2(3), 191-201. 
Harlow, H.F., \& Suomf, S.J. Induced depression in monkeys. Behavioral Biology, 1974, 12, 273-296.

Herson, M., Eisler, R.M., Alford, G.S., \& Agras, W.S. Effects of token economy on neurotic depression: An experimental analysis. Behavior Therapy, 1973, 4, 392-397.

Hinde, R.A., Spencer-Booth, Y., \& Bruce, M. Effects of six day maternal deprivation on rhesus monkey infants. Nature, 1966, 210, 1021-1033. Hrinda, P.D., vonKulmiz, P., \& Stretch, R. Pharmacological modification of experimental depression in infant macaques. Psychopharmacology, $1979,64,89-93$.

Klein, D.C., \& Seligman, M.E.P. Reversal of performance deficits and perceptual deficits in learned helplessness and depression. Journal of Abnormal Psychology, 1976, 85, 11-26.

Leshner, A.I., Remler, H., Bigeon, A., \& Samuel, D. Desmethylimipramine (DMI) counteracts learned helplessness in rats. Psychopharmacol으y, $1979,66,207-208$.

Lewinsohn, P.M., Weinstein, M.S., \& Shaw, D. Depression: A clinical research approach. In R.D. Rubin \& C.M. Franks (Eds.), Advances In behavior therapy. New York: Academlc Press, 1969. Looney, T.A., \& Cohen, P.S. Retardation of fump-up escape responding in rats pretreated with different frequencies of noncontingent electfic shock. Journal of Comparative and Physiological Psychology, 1972, 78, 31.7-322. Maler, S.F., Albin, R.W., \& Testa, T. Fallure to learn to escape shock in rats previously exposed to inescapable shock depends on nature of escape response. Journal of Comparative and Physiological Psychology, 1973, 85, 581-592. 
McKinney, W.T., Young, L.D., \& Suomi, S.J. Chlorpromazine treatment of disturbed monkeys. Archives of General Psychiatry, 1978, 35, $321-325$.

Melges, F.T., \& Bowlby, J. Types of hopelessness in the psychopathological process. Archlves of General Psychlatry, 1969, 21, 240248.

Menzel, E.W., Davenport, R.K., \& Rogers, C.M. Effects of environmental restrictions upon the chimpanzee's responsiveness to objects. Journal of Comparative and Physlological Psychology, 1963, 56, 78-85.

Miller, W.R., \& Sellgman, M.E.P. Learned helplessness and depression in man. Journal of Abnormal Psychology, 1975, 84, 228-238. M1ller, W.R., Sellgman, M.E.P., \& Kurlander, H.W. Learned helplessness, depression and anxiety. Journal of Nervous and Mental Disorders, $1975,161,347-357$.

Overme1r, J.B., \& Seligman, M.E.P. Effects of inescapable shock upon subsequent escape and avoidance responding. Journal of Comparative and Physiological Psychology, 1967, 63, 28.

Porsolt, R.D., Bertin, A., \& Jalfre, M. Behavioral despair in mice: A primary screening test for ant1-depressants. Archives Internationale de Pharmacodynamie et Therap1e, 1977a, 225, 327.

Porsolt, R.D., LePlchon, M., \& Jalfre, M. Depression: A new animal model sensitive to antidepressant treatments. Nature, 1977b, 266, 730.

Porsolt, R.D., Bertin, A., \& Jalfre, M. "Behavioral despalr" In rats and mice: Strain differences and the effects of imipramine: European Journal of Pharmacology, 1978a, 51, 291. 
Porsolt, R.D., Anton, G., Blavet, N., \& Jalfre, M. Behavioral despair in rats: A new model sensitive to antidepressant treatments. European Journal of Pharmacology, 1978b, 47, 379-391

Relsinger, J.J. The treatment of anxiety-depression via positive reinforcement and response cost. Journal of Applied Behavior Analysis, $1972,5,125-130$.

Robertson, J., \& Robertson, J. Quality of substitute care as an influence on separation responses. Journal of Psychosomatic Research, $1972,16,261-265$.

Schecter, M.D., \& Chance, W.T. Nonspecificity of "behavioral despair" as an animal model of depression. European Journal of Pharmacology, In press.

Schlottmann, R.S., \& Seay, B.M. Mother-infant separation in the Java monkey (macaca 1rus). Journal of Comparative and Physlological Psychology, 1972, 29, 334-340.

Seay, B.M., Hansen, E.W., \& Harlow, H.F. Mother-infant separation in monkeys. Journal of Child Psychology and Psychiatry, 1962, 3 , 123-132.

Seligman, M.E.P. Helplessness. San Francisco: Freeman, 1975. Seligman, M.E.P., \& Beagley, G. Learned helplessness in the rat. Journal of Comparative and Physlological Psychology, 1975, 88(2), $534-541$.

Seligman, M.E.P., KleIn, D.C., \& Miller, W.R. Depression. In H. Leitenberg (Ed.), Handbook of behavior modification and behavior therapy. Englewood Cliffs, N.J.: Prentice-Hall, 1976. Seligman, M.E.P., \& Maier, S.F. Failure to learn to escape traumatic shock. Journal of Experimental Psychology, 1967, 74, 1. 
Seligman, M.E.P., Maler, S.F., \& Geer, J. The alleviation of learned helplessness in the dog. Journal of Abnormal Psychology, 1968, 73, 256-262.

Sel1gman, M.E.P., Rosellin1, R.A., \& Rozak, M.J. Learned helplessness in the rat: Time course, imminization and reversibility. Journal of Comparative and Physlological Psychology, 1975, 88, 542-547. Sherman, A.A., Allers, G.I., Henn, L.A., \& Petty, F. A neuropharmacologically relevant animal model of depression. Neuropharmacology, $1979,18,891-893$.

Spencer-Booth, Y., \& Binde, R.A. The effects of separating rhesus monkey infants from their mothers for six days. Journal of Child Psychology and Psychiatry, 1967, I, 179-197.

Suomf, S.J., Seaman, S.F., Lewis, L.K., DeL1z1o, R.D., \& McK1nney, W.T. Effects of imipramine treatment in separation-induced social disorder in rhesus monkeys. Archives of General Psychlatry, 1978, 35, 321-325.

Taulbee, E.S., \& Wright, W.W. A psycho-soctal-behavloral model for therapeutic intervention. In C.D. Speilberger (Ed.), Current topics in clinical and community psychology. III. New York: Academic Press, 1971.

Turner, C., Davenport, R., \& Rogers, C. The effect of early deprivation on the social behavior of adolescent chimpanzees. American Journal of Psychiatry, 1969, 125, 1531-1536.

Wallach, M.B., \& Hedley, L.R. The effects of several antihistamines in a modified behavioral despair test. Federation Proceedings, 1979, 38, 861 . 
Welss, J.M., KrIckhaus, E.E., \& Conte, R. Effects of fear condltlonlng on subsequent avoidance behavior. Journal of Comparative and Phystological Psychology, 1968, 65, 413-421. 